\title{
Odporność na erozyjne zużycie strumieniowe napoin wykonanych drutem proszkowym samoosłonowym przy kącie padania ścierniwa $60^{\circ}$
}

\section{Wear resistance in erosive condition of hard-facing plates made with wire SSA and abradant impact angle $60^{\circ}$}

\section{Streszczenie}

W artykule omówiono napawanie i eksploatację płyt trudnościeralnych wykorzystywanych w przemyśle wydobywczym, pracujących w warunkach zużycia metal-minerał. Otrzymane wyniki prezentują właściwości dwóch napoin wykonanych z różnymi parametrami. Badania zużycia erozyjnego przeprowadzono z wykorzystaniem piaskarki przemysłowej przy kącie padania strumienia erozyjnego $60^{\circ}$. Trudne warunki pracy napoin wskazują na jednoczesny wpływ parametrów geometrycznych napoiny oraz jej właściwości mechanicznych i struktury na odporność na zużywanie.

\section{Abstract}

The paper shows the problem of exploitation and hard-facing of abrasive-resistant plates used in mining industry, working in the condition of metal-mineral wear. In the paper presented results refer to two hard-faced padding welds made according to different parameters. The research of the wear was carried out with the $60^{\circ}$ angle erosive stream. Severe conditions of work of hard-faced abrasive-resistant plates show the simultaneous role of hard-faced pad-ding weld geometrical parameters and its mechanical and structural properties in the wear resistance.

\section{Wstęp}

Trwałość części maszyn i urządzeń jest związana z parametrami eksploatacyjnymi, których wzrost powoduje przyśpieszone zużycie. Analiza przyczyn zużycia części maszyn i urządzeń wykazuje, że ok. $50 \%$ części ulega zużyciu ściernemu, 15\% adhezyjnemu, $15 \%$ zmęczeniowemu, $5 \%$ w wyniku korozji, a $14 \%$ wskutek łącznego działania tych proce-

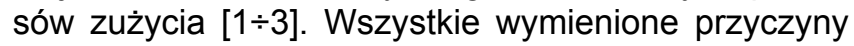
zużycia można odnaleźć w procesie eksploatacji napoin odpornych na zużycie ścierne, wykorzystywanych przez szeroko rozumiany przemysł wydobywczy.

Dr inż. Marek Gucwa, dr inż. Robert Bęczkowski - Politechnika Częstochowska.
Zużycie części maszyn i urządzeń w tym przypadku jest najczęściej wynikiem tarcia powierzchni metalowych o przerabiane minerały.

Zużycie ścierne metal-minerał następuje wówczas, gdy w obszarze tarcia występują luźne lub utwierdzone cząstki ścierniwa [1]. W praktyce można wyróżnić trzy podstawowe rodzaje zużycia ściernego tego typu:

- rysowanie lub bruzdowanie materiałem ściernym działającym pod małym obciążeniem (rynny zsypowe materiałów sypkich),

- mikroskrawanie materiałem ściernym działającym pod dużym obciążeniem (młyny kulowe, zęby kół zębatych, mieszarki itp.),

- żłobienie dużymi cząsteczkami działającymi pod dużym obciążeniem (czerpaki koparek, walce kruszarek skał itp.). 
Ekonomicznym sposobem przywracania cech użytkowych zużytym częściom jest napawanie regeneracyjne. Oprócz napawania regeneracyjnego stosuje się napawanie na nowe części maszyn i urządzeń. Jest to tzw. napawanie prewencyjne lub technologiczne $[1,4]$. Stały rozwój technologii spawalniczych oraz inżynierii materiałowej, daje możliwość wytwarzania napoin o właściwościach jakie nie były dawniej osiągalne. Dzięki temu wzrasta trwałość maszyn i urządzeń nawet $w$ trudnych warunkach eksploatacji, które można spotkać np. w przemyśle wydobywczym. Szczególnie narażone na zużycie są płyty i rynny przesypowe używane $w$ transporcie materiałów sypkich.

W wykonanych badaniach porównano właściwości napoin wykonanych różnymi parametrami i zbadanie ich wpływu na odporność na zużywanie tak przygotowanych napoin. Napoiny te mogą być wykorzystywane do wytwarzania wspomnianych wcześniej płyt, jak również jako wykładziny boków taśmociągów.

\section{Materiały do badań}

Jako podłoże do badań wybrano stal konstrukcyjną niestopową ogólnego przeznaczenia S235 o składzie chemicznym podanym w tablicy I. Grubość blachy wynosiła $10 \mathrm{~mm}$.

Tablica I. Skład chemiczny stali S235

Table I. Chemical composition of S235 steel

\begin{tabular}{|c|c|c|c|c|r|}
\hline \multicolumn{7}{|c|}{ Skład chemiczny stali, \% } \\
\hline C & $M n$ & Si & P & S & Al \\
\hline 0,22 & 1,10 & $0,10-0,35$ & 0,050 & 0,050 & 0,020 \\
\hline
\end{tabular}

Tablica II. Skład chemiczny drutu proszkowego

Table II. Chemical composition of flux-care wire

\begin{tabular}{|c|c|c|c|}
\hline \multicolumn{4}{|c|}{ Skład chemiczny drutu proszkowego, \% } \\
\hline $\mathrm{C}$ & $\mathrm{Cr}$ & $\mathrm{Nb}$ & $\mathrm{B}$ \\
\hline 5,4 & 22 & 7 & + \\
\hline
\end{tabular}

Tablica III. Parametry procesu napawania

Table III. Hard-facing parameters

\begin{tabular}{|l|c|c|}
\hline \multicolumn{1}{|c|}{ Parametry } & Napoina 4 & Napoina 7 \\
\hline Szerokość zakosów, mm & 25 & 25 \\
\hline Energia liniowa napawania, $\mathrm{kJ} / \mathrm{mm}$ & 3,27 & 3,72 \\
\hline Długość wolnego wylotu elektrody, mm & 20 & 40 \\
\hline Odbiór ciepła, W/mK & 4,3 & 4,3 \\
\hline
\end{tabular}

Tablica IV. Średnie wartości parametrów geometrycznych napoin Table IV. Average values of geometrical parameters of the padding welds

\begin{tabular}{|l|c|c|}
\hline \multicolumn{1}{|c|}{ Parametry } & Napoina 1 & Napoina 2 \\
\hline Szerokość napoiny, $\mathrm{mm}$ & 35,33 & 32,67 \\
\hline Wysokość napoiny, mm & 4,01 & 5,12 \\
\hline Głębokość wtopienia, mm & 1,64 & 1,06 \\
\hline Udział materiału podłoża w napoinie, \% & 32,14 & 22,24 \\
\hline
\end{tabular}

Do wykonania napoiny wybrano drut proszkowy samoosłonowy Corthal 61 o średnicy $2,8 \mathrm{~mm}$ i podanym przez producenta składzie chemicznym zamieszczonym w tablicy II. Napoiny wykonane tym drutem są przeznaczone do pracy w warunkach zużycia ściernego typu metal-minerał.

Aby zrealizować cel badań, wykonano 2 napoiny jednowarstwowe $z$ różnymi parametrami procesu. Proces napawania został przeprowadzony na stanowisku do napawania automatycznego ANAP-1 w Zakładach Produkcyjno-Remontowych KWB BOT Bełchatów S.A. Parametry procesu napawania umieszczono w tablicy III.

Efektem napawania z założonymi parametrami było uzyskanie 2 napoin o parametrach geometrycznych przedstawionych $w$ tablicy IV. W tej samej tablicy zamieszczono również udziały materiału podłoża w napoinie, który obliczany jest jako stosunek powierzchni przekroju nadtopionego metalu podłoża do sumy powierzchni przekroju nadlewu napoiny oraz metalu podłoża:

$$
U_{p}=\frac{F_{w}}{F_{n}+F_{w}} \cdot 100 \%
$$

gdzie: $U_{p}$ - udział materiału podłoża w napoinie, $F_{w}$ - powierzchnia przekroju nadtopionego metalu podłoża, $F_{n}$ - powierzchnia przekroju nadlewu napoiny

Udział materiału podłoża w napoinie jest stosunkowo duży, jednak już w pierwszej warstwie napoiny można zapewnić wymagane właściwości eksploatacyjne $\mathrm{W}$ większości metod napawania mały udział metalu podłoża $\mathrm{w}$ napoinie można uzyskać przez zmniejszenie energii liniowej procesu, czyli ilorazu mocy i prędkości napawania. Jednak zmniejszenie energii liniowej pociąga za sobą spadek wydajności napawania i ekonomiczności całego procesu, a w skrajnych przypadkach może uniemożliwić prawidłowe wtopienie i przyczynić się do powstawania przyklejeń. Napoina 2 była wykonywana przy wyższej energii liniowej, jednak zwiększony odcinek wolnego wylotu elektrody spowodował powstanie mniejszego wtopienia w materiał podstawowy oraz zmniejszył stopień wymieszania napoiny z materiałem podłoża.

\section{Badania strukturalne}

W celu przeprowadzenia badań metalograficznych zostały wykonane zgłady poprzeczne. Do trawienia przygotowanych zgładów użyto odczynnika o składzie chemicznym: $80 \mathrm{ml} \mathrm{C}_{2} \mathrm{H}_{5} \mathrm{OH}, 10 \mathrm{~g}$ chlorku żelaza $\mathrm{FeCl}_{2}, 10 \mathrm{ml} \mathrm{HCl}$.

Badania metalograficzne zostały wykonane na mikroskopie optycznym Axiovert 41. Stosując ten sam materiał dodatkowy, a zmieniając część parametrów procesu napawania, osiągnięto duże zróżnicowanie struktury. Jest to szczególnie widoczne, gdy porównuje 
się wielkość i kształt wydzieleń węglikowych w badanych napoinach. Przedstawione mikrostruktury pochodzą ze środkowych części napoin (rys. 1, 2).

Struktura napoiny 1 charakteryzuje się dużą dyspersją z licznymi węglikami pierwotnymi, przy czym ich wielkość zmniejsza się od powierzchni w kierunku linii wtopienia. W napoinie tej można zauważyć w strukturze występowanie węglików pierwotnych w postaci wielokątów i liczne drobne wydzielenia węglików eutektycznych. Struktura napoiny 2 składa się z wydzieleń węglików pierwotnych o kształcie podłużnym i nieregularnym w otoczeniu osnowy austenitycznej i drobnych węglików eutektycznych. Należy zaznaczyć, że w przypadku tej próbki widać wyraźną dominację nieregularnych wydzieleń i przynajmniej częściowo przypadkowe zorientowanie węglików o wydłużonym kształcie. Cechą charakterystyczną badanych napoin jest rozdrobnienie węglików, które zwiększają się z odległością od powierzchni i jest wywołane większymi prędkościami odprowadzania ciepła w kierunku materiału rodzimego. W tablicy $\mathrm{V}$ zamieszczono wyniki pomiarów udziału objętościowego węglików w strukturze w zależności od miejsca badania. Badania te wykonano z wykorzystaniem programu Olympus Stream.

Tablica V. Udział objętościowy węglików w strukturze Table V. Volume part of carbides in the structure

\begin{tabular}{|l|c|c|}
\hline Udział objętościowy węglików, \% & Napoina 1 & Napoina 2 \\
\hline Powierzchnia napoiny & 31,9 & 41,64 \\
\hline Środek napoiny & 34,4 & 43,18 \\
\hline W pobliżu linii wtopienia & 30,34 & 38,16 \\
\hline Średnia & 32,21 & 40,99 \\
\hline
\end{tabular}
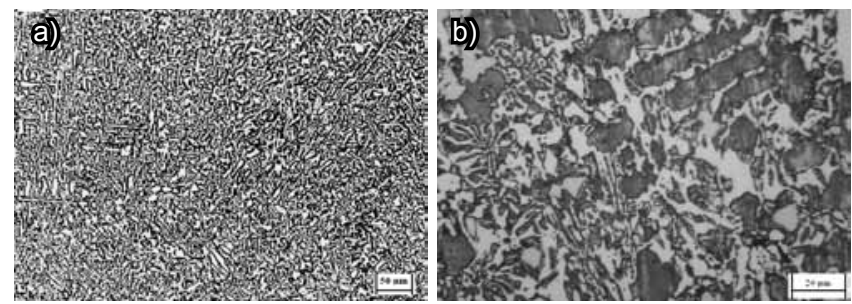

Rys. 1. Mikrostruktura napoiny 1: a) powiększenie 100x, b) powiększenie $500 x$

Fig. 1. Microstructure of padding weld 1: a) magnification 100x, b) magnification $500 x$
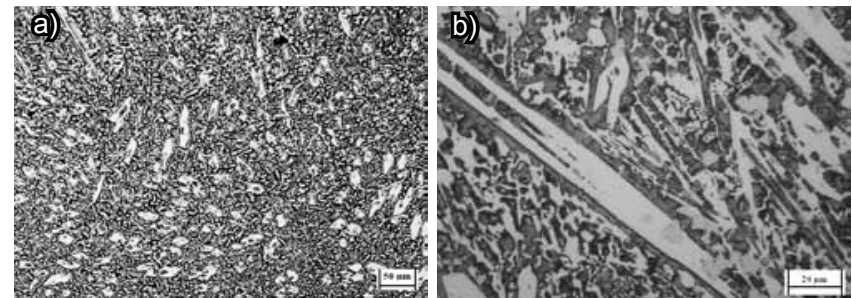

Rys. 2. Mikrostruktura napoiny 2: a) powiększenie 100x, b) powiększenie $500 x$

Fig. 2. Microstructure of padding weld 2: a) magnification 100x, b) magnification $500 x$

\section{Badanie twardości}

Badanie twardości wykonano na przygotowanych próbkach metodą Vickersa przy obciążeniu 294,2 N. Badania przeprowadzono w kierunku wzdłużnym oraz poprzecznym, a ich wyniki przedstawiono na rysunkach 3 i 4 . Twardość w kierunku wzdłużnym była mierzona na całej długości napoiny w odległości $2 \mathrm{~mm}$ od jej powierzchni. Twardość w kierunku poprzecznym była mierzona w środkowej części napoiny, od jej powierzchni do linii wtopienia.

Z przedstawionych badań wynika, że napoina 1 charakteryzuję się mniejszą twardością niż napoina 2. Można tłumaczyć to mniejszym udziałem węglików w strukturze napoiny 1 oraz większym stopniem udziału materiału podłoża w napoinie, który wynosi $32,14 \%$ w porównaniu do $22,24 \%$ w napoinie 2 .

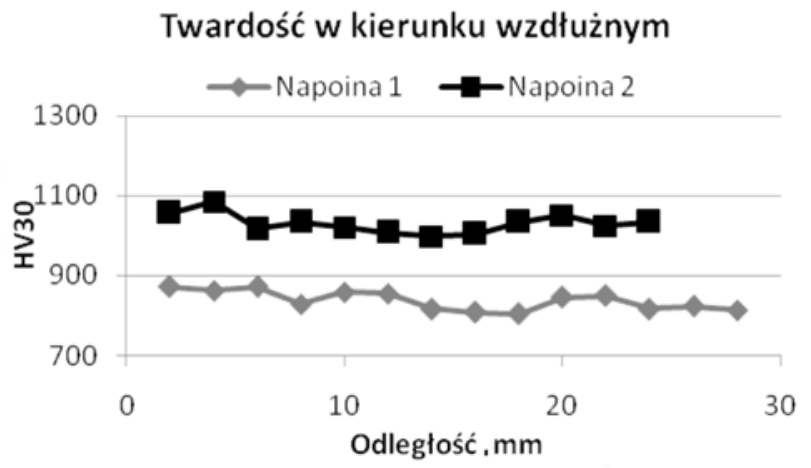

Rys. 3. Twardość napoin w kierunku wzdłużnym

Fig. 3. Hardness in the longitudinal direction

Twardość w kierunku poprzecznym

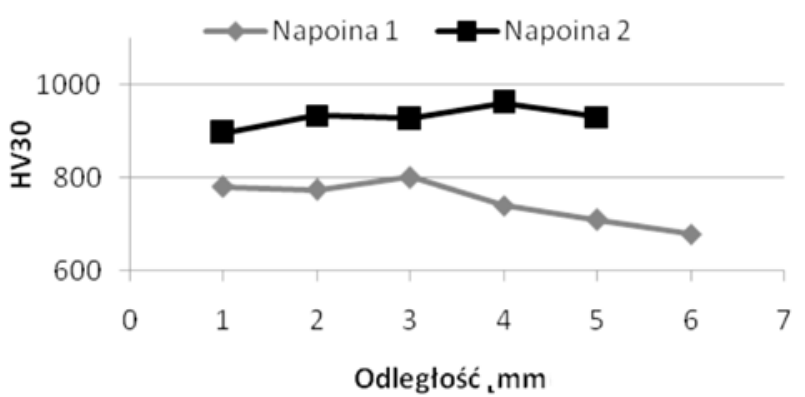

Rys. 4. Twardość napoin w kierunku poprzecznym

Fig. 4. Hardness in the lateral direction

\section{Badanie odporności na erozyjne zużywanie strumieniowe}

Kolejną badaną właściwością napoin była ich odporność na erozyjne zużywanie strumieniowo przy kącie padania strumienia $60^{\circ}$. W tym celu posłużono się piaskarką przemysłową, a najważniejsze parametry pracy piaskarki były następujące: ciśnienie $8 \mathrm{~atm}$, wydajność ścierniwa $13 \mathrm{~kg} / \mathrm{min}$, średnica dyszy $9 \mathrm{~mm}$, odległość dyszy od próbki ustalono na $100 \mathrm{~mm}$. 


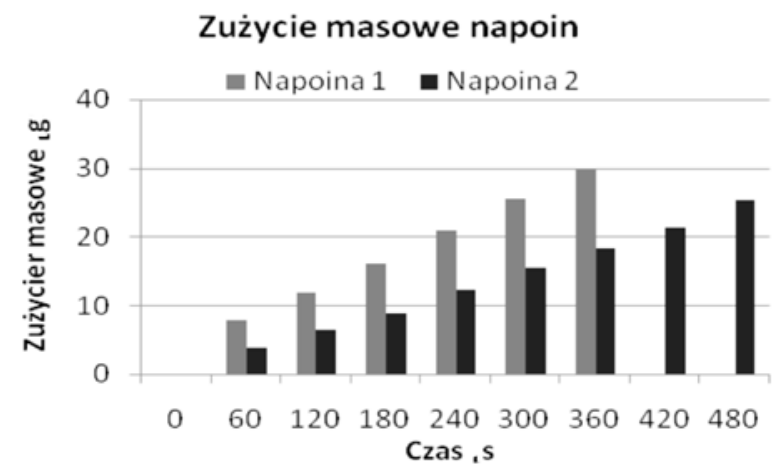

Rys. 5. Zużycie masowe

Fig. 5. Massive wear

Jako erodentu użyto ścierniwa kwarcowego o ziarnistości $0,5 \div 2 \mathrm{~mm}$. Do badań przygotowano próbki o wymiarach $40 \times 50 \mathrm{~mm}$, które zostały umieszczone w specjalnym uchwycie pod kątem $60^{\circ}$ względem dyszy. Badanie procesu zużycia erozyjnego przebiegało $\mathrm{w}$ ten sposób, że po minucie pracy piaskarki mierzono ubytek masy próbki za pomocą wagi elektronicznej Vibra model AJH-620CE o nośności 620 gramów i dokładności odczytu do 0,001. Następnie próbka była badana wizualnie, ponownie montowana i poddawana procesowi zużycia przez następną minutę. Całość operacji powtarzano, aż do stwierdzenia zużycia warstwy napoiny do materiału rodzimego. Zużycie masowe $Z$ było obliczane ze wzoru:

$$
Z=m_{p}-m_{t}
$$

gdzie: $m_{p}$ - masa początkowa, $m_{t}-$ masa po procesie ścierania

Wskaźniki zużycia, czyli intensywność zużycia oraz odporność na zużycie są znane i używane w opisie zjawisk trybologicznych. Zwykle intensywność zużycia odnosi się do drogi, na jakiej zaszło to zużycie. W tym przypadku jednak zdecydowano się, na podstawie literatury, odnosić intensywność zużycia do masy ścierniwa, jakie zostało użyte w jednostce czasu [3].

$Z$ analizy otrzymanych wyników dotyczących zużycia widać, że napoina 2 charakteryzuje się większą

\section{Wnioski}

Parametry procesu napawania mają istotny wpływ na rodzaj powstającej struktury i jej właściwości. llość węglików w strukturze napoiny 2 jest większa o $27 \%$ w stosunku do napoiny 1 . Pociąga to za sobą wzrost twardości, co w tym przypadku przekłada się w sposób bezpośredni na wzrost odporności na zużywanie.

Zwiększenie długości wystającego odcinka elektrody powoduje wzrost wydajności stapiania, co pociąga za sobą powstanie mniejszego wtopienia oraz zmniejszenie stopnia wymieszania napoiny z materiałem podłoża.

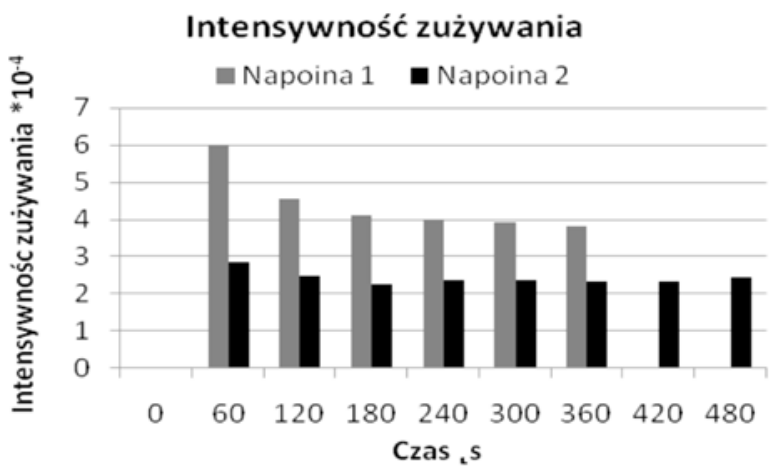

Rys. 6. Intensywność zużywania

Fig. 6. Wear intensity

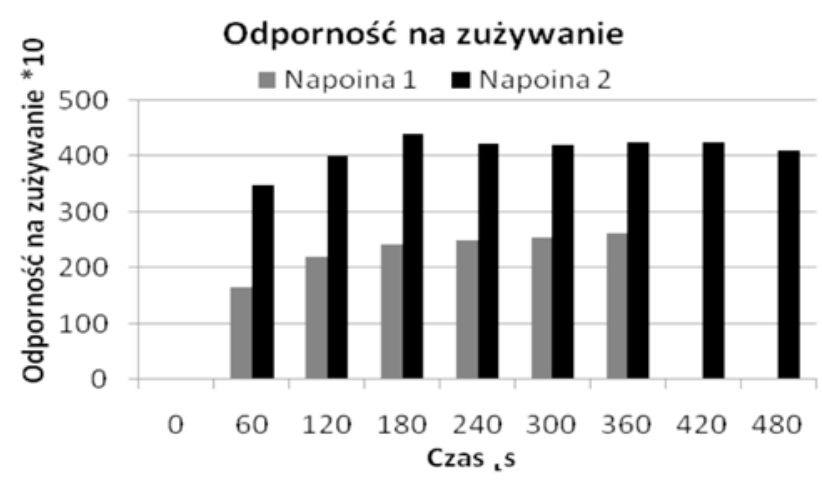

Rys. 7. Odporność na zużywanie

Fig. 7. Wear resistance

odpornością na zużywanie $\mathrm{w}$ stosunku do napoiny 1

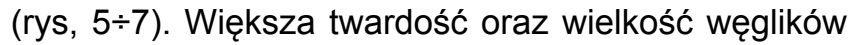
w napoinie 2 wpływają korzystnie na wzrost odporności na zużywanie $w$ tym systemie trybologicznym. Dodatkowo napoina 2 ma większą wysokość nadlewu oraz mniejszy stopień wymieszania materiału podłoża z napoiną. Czynniki te powodują, że napoina 2 charakteryzuje się $w$ tym przypadku większą trwałością. Należy pamiętać, że twardość nie może by jedynym wyznacznikiem określającym odporność na zużywanie.

\section{Literatura}

[1] Klimpel A.: „Napawanie i natryskiwanie cieplne-technologie”, WNT, Warszawa 2000.

[2] Womerslay D.: Hardfacing:not merely a reclamation process. Surface Engineering nr 1/1995, s. 43-46.

[3] Hejwowski T.: Studium procesów zużywania erozyjnego, ściernego i zmęczenia cieplnego elementów maszyn oraz kształtowanie struktur o korzystnych właściwościach eksploatacyjnych, Wydawnictwo Politechniki Lubelskiej 2003.

[4] Dziubiński J., Adamiec P.: Napawanie i natryskiwanie wczoraj i dziś, Przegląd Spawalnictwa, nr 5/1998, s. 6-8. 